\title{
Diversity and Inclusion in the Mining and Minerals Industry: The Zimbabwe Perspective
}

\author{
Oswell Binha \\ PhD Candidate, Africa University, College of Business Peace Leadership and Governance \\ DOI: 10.29322/IJSRP.11.09.2021.p11724 \\ http://dx.doi.org/10.29322/IJSRP.11.09.2021.p11724
}

\begin{abstract}
Although Zimbabwe's mining sector ministry is optimistic of attaining a 12 billion mining economy by 2023, diversity and inclusion continue to hinder the set target. Factors causing lack of diversity and inclusion in the mining industry include but are not limited to negative perceptions and attitudes about women's potential in mining, lack of women role models to look up to, lack of mining equipment and facilities designed specifically for women, financial and workplace pressures, bureaucracy in acquiring mining claims and limited access to credit for boosting or starting mining ventures. However, while acknowledging Zimbabwe's population demographics, much still needs to be done for Zimbabwe to promote full inclusion and diversity in Zimbabwe's mining value chain. Zimbabwe's population demographics account for over half the population being women.
\end{abstract}

Index Terms- diversity and inclusion, empowerment, mining and minerals, small-scale artisanal mining, affirmative action, sustainability.

\section{INTRODUCTION}

M ining is one of the prehistoric economic activities currently still in operation in most African countries. Its potential contribution to economic development remains unmatched in that the sector is a mass employer. The mining and minerals industry promotes infrastructural development, thereby boosting other downstream linkages, economic activities and social services of mining communities. Mining investments are supported by are various economic sectors such as transport, banking, manufacturing and agriculture. However, the industry remains disproportionate, mainly in its personnel demography, as Women remain underrepresented in large-scale underground parts of the mining operations. The proportion of female employees in the Mining and minerals sector, containing barely 5-10\% of the global workforce, is one of the smallest among all global economic sectors (Ledwaba, 2017; Macdonald, 2017; WIM (U.K.) and PwC, 2013.

The mining industry in Zimbabwe is a typical maledominated sector. In 2017 Zimbabwe had at least 42 large scale miners and an estimated 50000 small scale artisanal miners. Women continue to be under-represented in the Zimbabwe mining industry, filling only $15 \%$ of jobs. According to Women in Mining (WIM), almost 7000 of the 30000 registered small-scale miners in Zimbabwe are women, and other reports indicate that it is tough for a woman to solo own a mine in Zimbabwe, and this brings to the reality that diversity and Inclusion in Mining continue to be an intangible dream. Many mining companies around the globe have embarked on journeys to increase the number of women within their organisations by improving inclusion diversity.

Zimbabwe is a top mining country in Sub Saharan Africa, accounting for the second biggest global producer of platinum, a fifth global producer of lithium, and substantial Gold, Chrome, tantalite, and nickel. According to the 2016 national census, the women population accounts for $52 \%$ of the Zimbabwean population. It, therefore, is necessary to identify weaknesses in the existing public policy and discuss strategies necessary for possible policy realignment for increased women participation in the mining and minerals sector, including potential sector upgrades. The potential impacts of mining and minerals on women communities and women's socio-economic and sociopolitical characteristics as miners are relevant in Zimbabwe's economic development initiatives. Zimbabwe appears not to have acknowledged the role Diversity and Inclusion play in the mining and minerals sector productivity. Globally, women entrepreneurs' reputation in pursuit of sustainable livelihoods and poverty alleviation is not debatable. Zimbabwe must exploit indigenous peoples right to gender equity and gender mainstreaming in the mining and minerals sector, particularly in artisanal and smallscale mining.

\section{THE OBJECTIVE OF THE STUDY}

- The paper intends to give an in-depth understanding of the current state of inclusion and diversity in the Zimbabwe Mining and minerals industry.

- Identify challenges and opportunities in pursuit of achieving desired inclusivity and diversity thresholds in the Zimbabwe mining and minerals industry

- Identify existing networks that focus on supporting women in mining.

- To provide policy recommendations in support of diversity and inclusion in the mining sector

\section{RESEARCH QUESTIONS}

- What is the current state of inclusion and diversity in the Zimbabwe Mining and minerals industry? 
- What are the challenges and opportunities in pursuit of achieving desired inclusivity and diversity thresholds in the Zimbabwe mining and minerals industry

- What are the existing networks that focus on supporting women in mining

\section{JUSTIFICATION OF THE STUDY}

This study is pertinent in that the more significant part of Africa is mineral dependant on its economic development. In 2021 forecasts a double-digit growth regardless of the obtaining capital constraints with $32 \%$ gold output growth, to approximately 33000 $\mathrm{kg}$ up $25000 \mathrm{~kg}$ in 2020. The Chamber of Mines anticipates a slight increase of $3 \%$ in the PGMs sector to account for the expected $15000 \mathrm{kgs}$ in 2021 . The mining and minerals industry generates employment opportunities at a large scale and fosters infrastructural development, among other necessary activities. Hence, if diversity and inclusion are not adequately addressed in the mining sector, it will negatively affect economic growth in Zimbabwe and the continent at large. Diversity and inclusion demonstrate the equitability of macroeconomic development. Addressing gender inequity in male-dominated industries such as the mining and minerals sector will serve as a guide in closing extreme disparity gaps not only in incomes variables but other related socio-economic inequalities. Diversity and inclusion, if well tackled, may respond to poor literacy and mobility, low employment and income-generating opportunities, poor reproductive health choices and preferences and poor quality of marital relationships and communication in women.

\section{Problem Statement}

Considerable focus has been on including women in the mining industry and capturing women's socio-economic experiences within mining communities (Lahiri-Dutt 2011). Emerging literature has shown that the inclusion of women is key to ensuring sustainability within mining communities and as an economy. This comes with the perception that women's dedication and diligence may improve mining companies' performance (Ranchod, 2001). Musvoto (2001) asserted that female employees are an asset to the mining industry and that their vigilant character could promote a safer working environment. Women comprise $11 \%$ of the total workforce in the Zimbabwe mining industry. Current trends in technological improvements may be a catalyst to accelerated diversity and inclusion in Zimbabwe. The traditional mining and minerals exploitation that served as justification for elaborate imbalances in the sector may be checked. Underrepresentation of women in Zimbabwe mines persists, particularly in managerial and underground positions, thereby retaining the industry's reputation as a "male-dominated and chauvinistic society. Against this background, the research aims to probe into women's occupational experiences within the mining industry to understand women's challenges and barriers. Macroeconomic challenges affecting other sectors of the economy natural locate the mining and minerals sector as the leading employer and hence the need for accelerated diversity and inclusion.

Whilst gender mainstreaming in workplaces provides a rare opportunity for public policy to respond to female miners limitations in their productive capacities and broad-based empowerment in the sector. Zimbabwe has previously introduced affirmative action policies and procedures that demonstrate African feminism synonymous with socio-economic and sociopolitical linkages of historical multicultural African perspectives.

\section{Zimbabwe Mining Sector contribution}

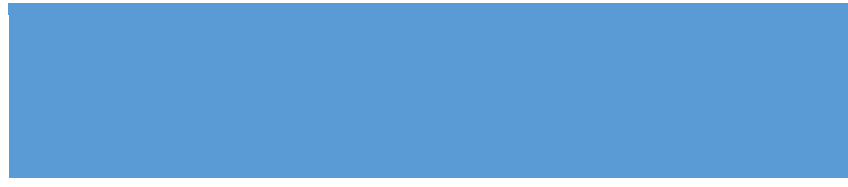

Mining Contribution to GDP

Mining contribution to Export earnings

Mining contribution to employment
$23 \%$

Source: Zimstats 2019 


\section{DEFINING DIVERSITY AND INCLUSION}

Diversity in the workplace is conceptualised as not only about fair representation of diverse socio-cultural identities (race, ethnicity, religion), physical attributes (or disabilities), age, gender, language, sexual orientation, and so on, but also about respecting and valuing differences (Ghorashi and Ponzoni, 2014) The workplace environment is about closing physical, social, and economic distances separating people and treating all individuals fairly and respectfully, giving them equal access to opportunities and resources, and contributing fully to the organisation's success.

The mining and minerals industry is progressively turning to Diversity and Inclusion (D\&I) to correct emerging issues of workforce demographics, growing communities and interested stakeholders awareness and indeed the ever-developing advanced mining and minerals sector technological solutions. Denial and intransigence on the part of the mining and minerals sector present barriers to access and lack of currently relevant information on D\&I emerging innovations in the mining and mineral extraction contexts, militating against simplified adoption and development of fresh current trends. Companies may generate tailor-made implementation, reporting and monitoring on their internal D\&I frameworks using properly designed simplified indicators. These indicators would capture everchanging demographics, mining and minerals sector policies and related regulations, ethnicity, among other workplace variables on D\&I indicators. Achieving milestones in SDG would provide corporate intention to align its operations around gender equity, diversity, inclusion and mainstreaming.

Iverson and Maguire (2000) discovered that there is a rapport between job fulfilment and life satisfaction for the majority of male mining and minerals sector employees in Australia. Components "of kinship support and family isolation, job satisfaction is the next most significant variable that affects life satisfaction" Deducing a comparative analysis from this study, one would draw a conclusion that there is a nexus between the diversity of lifestyles at both community and corporation. Mining and minerals sector players must therefore locate D\&I at the centre of their corporate sustainability plans deriving workplace coherence out of the diversity and inclusivity that comes with it.

Diversity and Inclusion - the gender dimension in mining

Women's role and contributions to the mining and minerals sector in large-scale and small-scale artisanal mining remains regularly neglected. Equally, the role and value of women from mining communities often remain unnoticed or underplayed. The Swedish experience demonstrates that mining and minerals sector players equally social sustainable development complications mainly emanating from the company-community interactions. These challenges astride the usually defined workplace culture and corresponding community -community cohesion is weakened because of mining and minerals sector interest groups, regulators and community leadership. The opportunity for elaborate D\&I is derailed because some influential interested stakeholders naturally reject innovative ideas and buttress conventional, patriarchal tendencies among the existing masculine beliefs. The Swedish experience, like in the Australian context, exposes the disparities in the diversity of workplace lifestyles, the gendered dimension, as well as associated working conditions.
Frederick Bird 2016 provides the argument on the mining and minerals sector strategic alliances, particularly with international mining firms exploiting mierals in developing countries. Fredrick demonstrates that these mining firms do not necessarily develop new sustainability strategies, but they tend to reinforce standards that create enclaves and are poorly integrated into the economies of host societies. This failure to undo enclaves in these communities ultimately foster inequitable and exclusive and selective wealth not suitable for broad-based development and engender inequalities in these countries.

\section{LITERATURE REVIEW}

Mayes and Pini (2014) suggested that increasing the recruitment and hiring of women in the mining sector or, in other words, "capitalising" on diversity is becoming a required step for many companies to become competitive in the market under the argument that more diverse companies perform better. Mayes and Pini (2014), increasing the recruitment and hiring of women in the mining sector or, in other words, "capitalising" on diversity is becoming a required step for many companies to become competitive in the market under the argument that more diverse companies perform better. In fact, "the employment of more women, far from becoming over time a taken-for-granted aspect of the industry, is restated in every report. Hinton et al. (2013) suggest that the number of women generally involved in largescale Mining in Africa is lower than those in artisanal mining. From an African perspective, historically and culturally, women have been restricted from performing underground mining activities. The male-controlled, patriarchal system in most black African societies obliges women to submit to men naturally. Buthelezi (2013) asserts that women's valuable contribution to the mining industry far outweighs the risks associated with their inclusion as employees in the operations.

The literature that discusses socially sustainable development in the mining industry from a gender perspective is not particularly extensive, although it is growing. The literature focuses mainly on mining in developing countries as well as on social problems. For example, Ahmad and Lahiri-Dutt (2006) and Lahiri-Dutt (2012a) note that women and men have welldemarcated gender roles in indigenous communities, so the impacts of mining on women and men are not the same. Whenever such a community suffers from the losses of environmental resources, Ahmad and Lahiri-Dutt argue, it is the women who suffer the most. In some cases, women have lost their work and relative economic independence and have to start earning a living in the informal sector (perhaps as sex workers). Indian women, especially those living in villages, do not have legal rights over land and are rarely titleholders of land. The compensation process usually assumes that the adult male is the head of the household and fails to consider the needs and requirements of women. Compensatory jobs, if any, usually go to men, and women risk unemployment. Nayak and Mishra (2005) add that the mining industry in India can contribute to sustainable development by promoting women's economic advancement and reducing women's poverty, ensuring greater involvement of women in the mining sector. In an Australian gender study, Lozeva and Marinova (2010) show that mining can negatively impact local 
communities, especially local women and the environment. They argue that there is an urgent need for the mining industry to transform itself in order to meet sustainability imperatives. LahiriDutt (2012a) also notes that in developing countries, both largescale, capitalised mining and small-scale, artisanal mining introduce rapid social changes that affect women more negatively than men. There are some exceptions in the literature that present more positive examples. Kemp et al. (2010) describe how one of the world's largest mining companies works to integrate gender considerations at the mine site. The company aims to counteract the male-centric mining industry by integrating gender. Mining and gender considerations must be at the centre of local community relations at all stages of the mine project development cycle, from exploration through construction, operation, and closure. The study, however, does not present any examples of long-term results such as organisational change at the mine-site level. Eveline and Booth (2002) describe how a new diamond mine in Australia had strategic plans to control the labour force by developing an industrial and economic stable environment, but the article concluded this attempt at social sustainability failed and resulted in almost the opposite. Gender issues were also included in a baseline study of the socio-economic effects of Northland Resources' planned mining activities in Pajala, Sweden and Kolari, Finland. The baseline study, commissioned by Northland
Resources, Inc., was carried out during 2007-2008 by a research team led by Professor Jan Johansson, Department of Human Work Science, Luleå University of Technology. The project included ten sub-studies: Demography, Labour Supply, Local trade, Infrastructure, Governance, Work environment, Gender, Preferences (of the citizens), Transnational history, and Indigenous people. The report on gender (Organisational gender aspects) describes how internal gender patterns are related to external conditions (Abrahamsson 2008). For example, explanations of the very low percentage of women in mining can be found in culture, the labour market, and educational traditions at the national level, at the regional/local level, as well as within the mining companies themselves. The report presents an optimistic and, at that time, somewhat provocative scenario where more women want to stay in the region and more women are employed in the mine. This also includes a change in attitudes and opportunities, meaning that more girls choose technical and industry programs in upper secondary school. It also includes a changing of local cultural attitudes about women and work, liberating them from old-fashioned feminine and masculine identities. This scenario also meant that men would work more steadily and closer to their homes, that

The African context

\begin{tabular}{|l|l|}
\hline Country & \% of women in mining \\
\hline South Africa & 26.6 \\
\hline Botswana & 21 \\
\hline Namibia & \\
\hline Zimbabwe & 18.7 \\
\hline
\end{tabular}

Source: World Bank 2019 


\section{Gender Equity in Key Deployments}

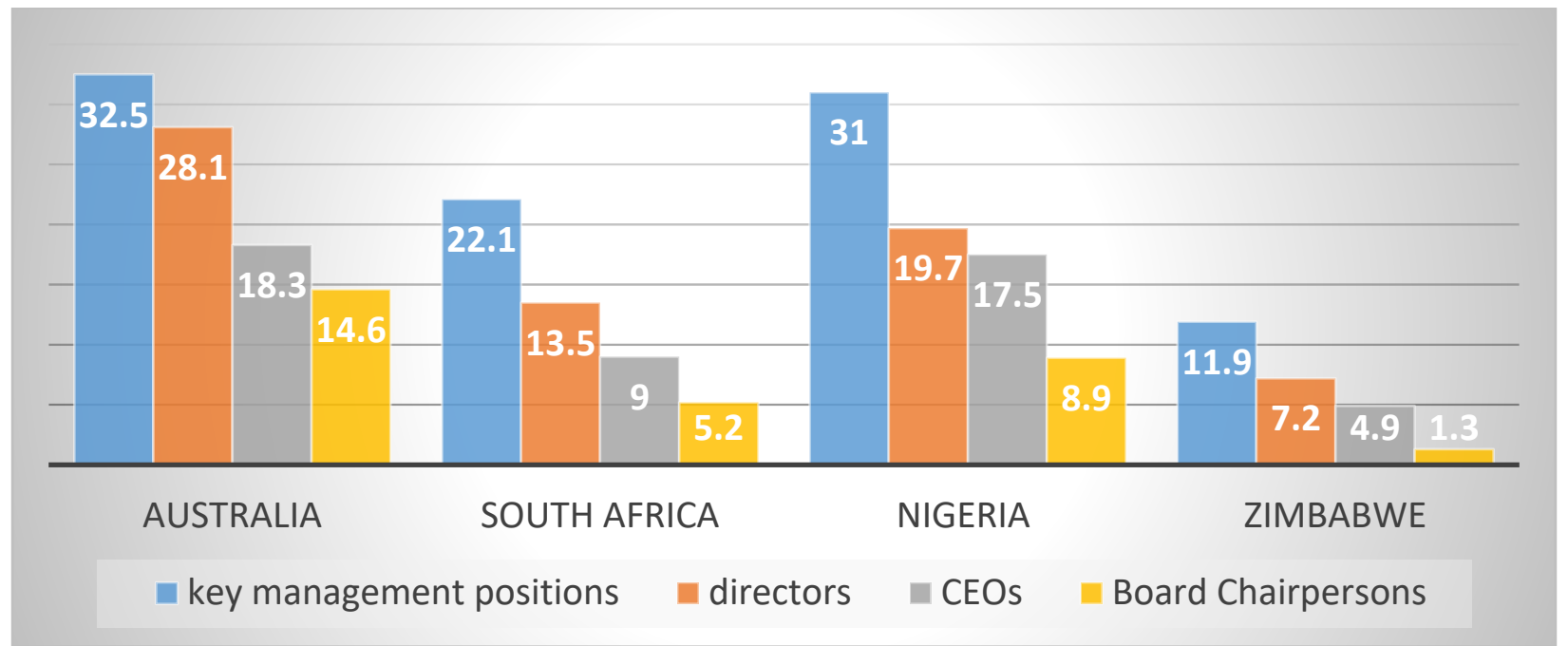

\section{GENDER DIMENSION: EMPOWERMENT}

Women's involvement in the mining and minerals sector through direct employment is moderately insignificant, and those who go into the sector tend to remain at the lowest levels of the administrative hierarchy. Nayak and Mishra (2005) add that the mining industry can contribute to sustainable development by promoting women's economic advancement and reducing women's poverty, ensuring more significant involvement of women in the mining sector. Mayes and Pini (2014) point out that boosting the employment and appointment of women in the Mining and minerals sector or, in other words, "capitalising" on diversity is becoming a required step for many companies to become competitive in the market under the argument that more diverse companies perform better.

Whilst some levels of empowerment legislation is a necessary condition for women empowerment; it is certainly not sufficient to achieve desired levels of D\&I in the mining and minerals sector in Africa. Gender-sensitive Legislation and gender supporting regulations may exist; it is the lethargy in complying with them that increases workplace diversity and inclusion challenges. As the women progress up the corporate ladder, career progression gender-related discriminations raise their ugly head manifested through instruments of decision making at the workplace, remuneration, decent work and dealing with immediate managers and supervisors. Skills and knowledge empowerment are essential, incapacitating the women as they prepare themselves for career growth.

The creation of legislated gender quotas in professional bodies and the economic sector has been argued as disempowering and retrogressive as it invokes resistance from the menfolk. It is said to make women be perceived as placeholders because they are a creation of affirmative action statute. In many instances, the legislated quota system may destroy the confidence of the deployees despite their competence levels.

Gender Dimension: Global Barriers versus Zimbabwe D\&I barriers

Conventional barriers to female participation in mining in the global industry include:

- hazardous conditions and security risks;

- infrastructure complications;

- physical requirements;

- remote workplace locations; and

- Discrimination

However, negative perceptions and attitudes about women's potential in mining, lack of women role models to look up to are symptomatic of Zimbabwe's D\&I potential. Zimbabwe lacks mining equipment and facilities designed specifically for women hence the belief that the mining and minerals sector is not womenfriendly. Studies have found out that if tailor-made financial packages are extended in the mining and minerals sector in Zimbabwe, the majority of them would experience less stress in integrating into the various levels at the workplace and would manage better workplace pressures.

Low education on mining skills as a consequence of low uptake at institutions of higher on hardcore mining and minerals courses accounts for the low numbers of women in the mining and minerals sector. Beyond the academic and professional development at institutions of higher learning, bureaucracy in acquiring mining claims and limited access to credit for boosting or starting mining ventures militate against the opportunity to increase women entrepreneurs in the mining and minerals sector. 
Zimbabwe Societal opinions on gender equality, equity, legal and policy restrictions, including lack of adequate support from the Government, perpetuates masculinity in the mining and minerals sector. For those women who eventually fight their way to work underground, they run the risk of many types of abuses, including sexual harassment and violence. Zimbabwe must ensure optimum conditions are existing for all to exploit opportunities for growth, including the availability of befitting Personal Protective Equipment (PPE) explicitly designed for women.

\section{Methodology}

The researcher adopted interpretive research philosophy to uncover the underlying perspectives of inclusion and diversity in Zimbabwe. The exploratory research purpose was selected as the most suitable to provide answers. The researcher used qualitative and quantitative data collection methods. Questionnaires were adopted as ideal instruments for primary data collection, with secondary data being gathered from company reports, published and unpublished articles, magazines, and government and research outputs from other organisations. A purposive sampling technique was preferred to select participants in this study

\section{Results Presentation}

\section{Gender}

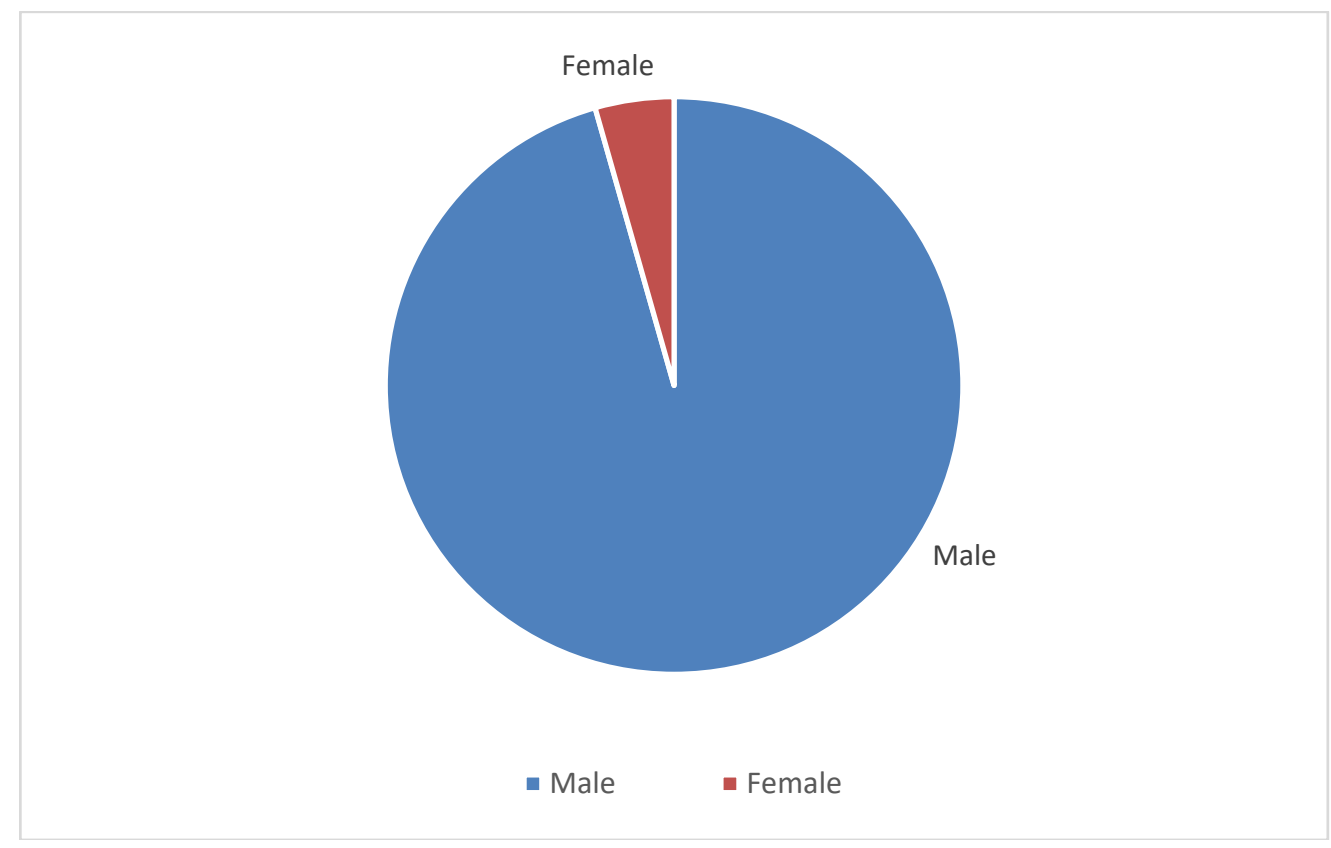

Of the total respondents, only $4 \%$ were female. This was further corroborated by secondary data findings that the mining industry in Zimbabwe is male-dominated.

Women in Leadership

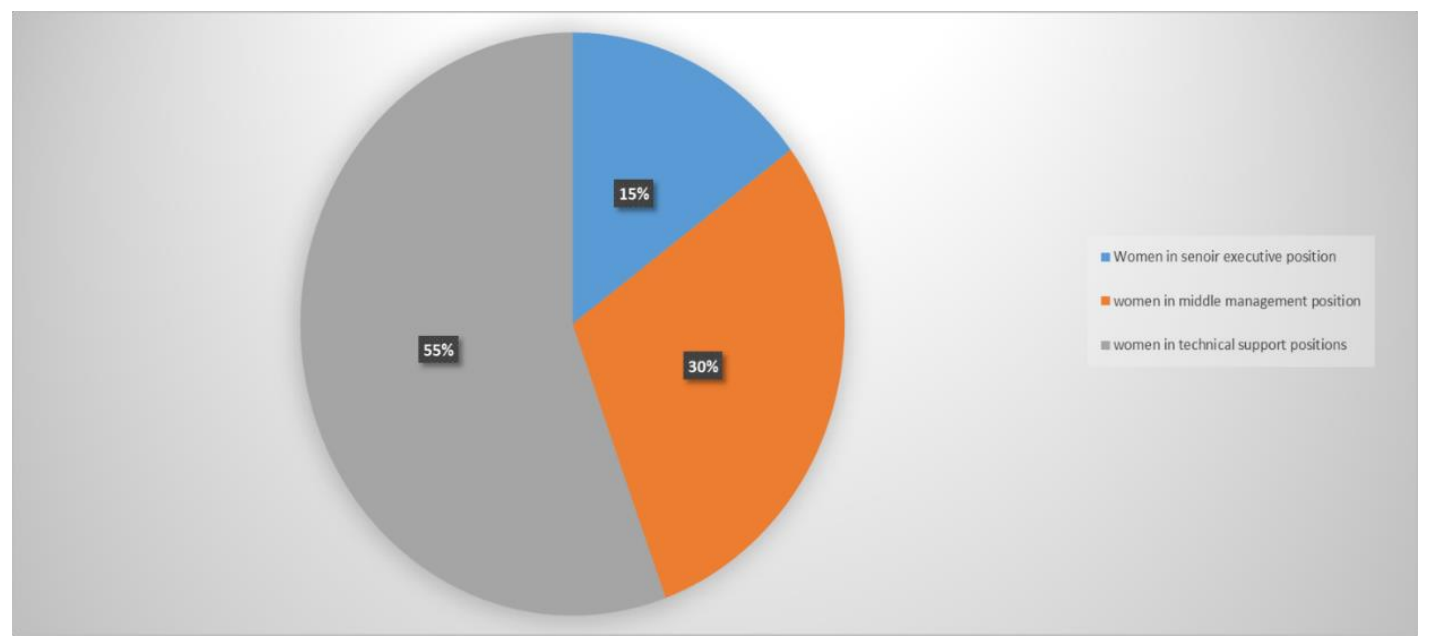


Results from the study indicate that most women in the mining industry offer technical support $55 \%, 30 \%$ are employed at managerial positions, and $15 \%$ offers extractive support. Few women are in extractive positions, which could be explained by the nature of mining jobs that they are hard labour which requires men than women

Education and Training Mix

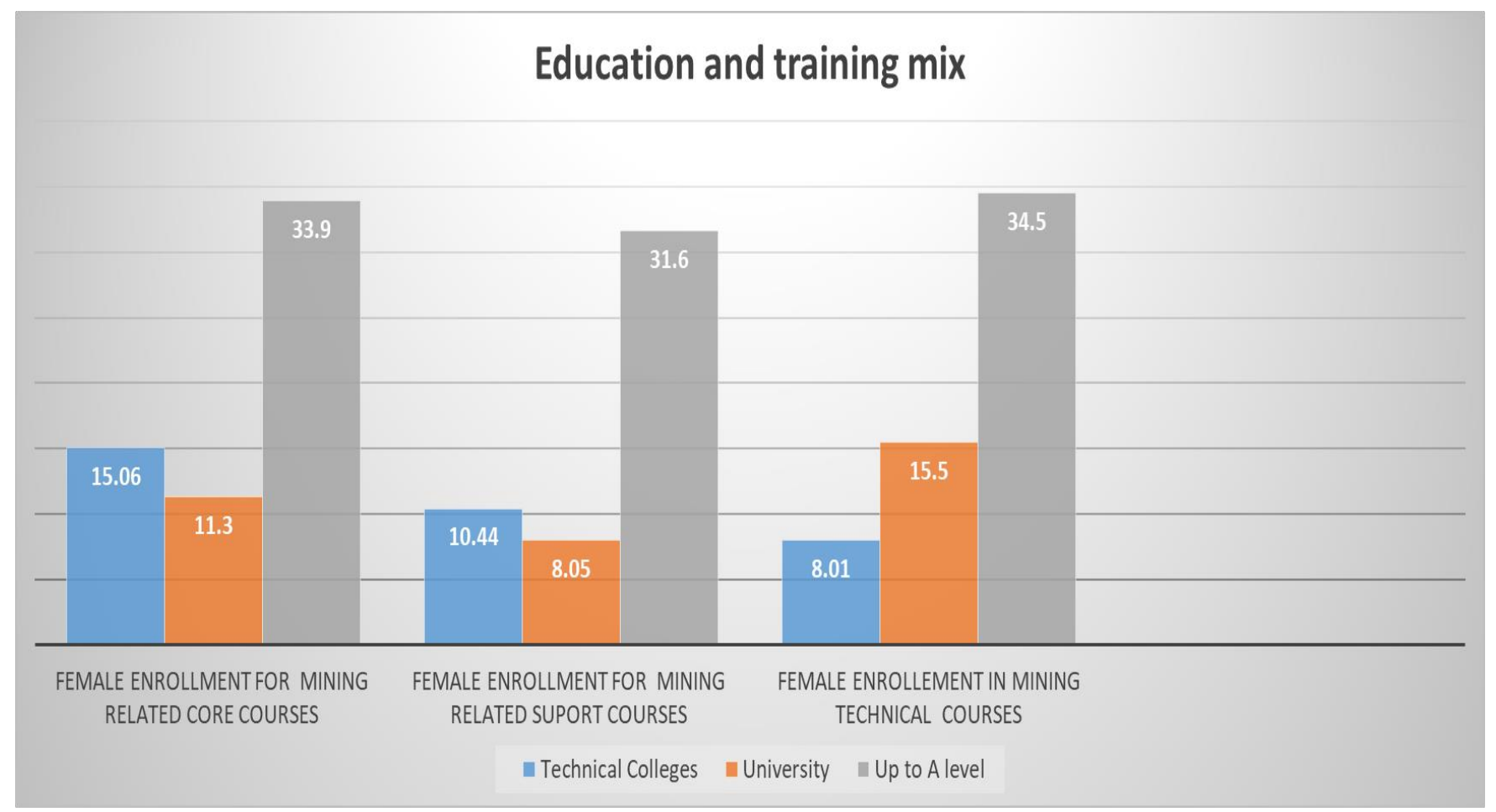

D\&I - the national policy conundrum

Zimbabwe's public and private sectors are making concerted efforts to close the mining opportunities divide that has been long overdue. For example, after realising that girls only contributed $21.9 \%$ of the total students enrolled at the Zimbabwe School of Mines in the past years, the institution tried to reach out to high school girls to encourage them on mining-related courses. In addition, the Zimbabwean Government introduced the Science, Technology, Engineering and Math (STEM) initiative to complement SADC's industrial initiative that also encompassed female students.

In the same vein, the Minerals Marketing Corporation of Zimbabwe (MMCZ) has also started rolling out training programs for youth artisanal and small-scale miners (including women) as a way of formalising them and boosting their production capacity. The Government has attempted to attract women in mining by offering them loans through the Reserve Bank of Zimbabwe and Women Bank. Through the parent Ministry of Women Affairs, Community, Small and Medium Enterprises Development, the Government of Zimbabwe re-introduced the Women Development Fund to promote women entrepreneurs and womenowned businesses in various sectors of the economy, including the mining and minerals sector and its heterogeneous value chain. Eligible women receive up to $\$ 400000$ to boost their business ventures.
In the private sector, companies like CEO Africa Roundtable are implementing a venture capital fund to see eligible women and youth in various sectors, including mining benefiting from the initiative. Fidelity Printers and Refiners, under its Gold Development initiative, once disbursed $\$ 18$ million for women in mining to boost their efforts.

Role of the Zimbabwe Gender Commission

\section{Role Modelling and Mentorship}

Zimbabwe is yet to adopt best practices in identifying and implementing mentorship initiatives in the mining and minerals sector. These initiatives are essential in the cross-fertilisation of cross-company knowledge platforms. They are useful in promoting and empowering women to access guidance as they progress with chosen mining and minerals sector careers. Mentorship and role modelling facilitate mentees to overcome any such professional challenges they may encounter, including confidence-building under-seasoned stewardship in preparation for the achievement of impending industry corporate and professional leadership. The foundation blocks of role modelling and mentorship must strongly emphasise tenets of diversity and inclusion. Mentors would empower mentees to identify and respond to perceived cultural barriers, create beneficial strategic alliances between the seasoned and those still learning the ropes in the mining and minerals industry. 
Does Zimbabwe have role models in the mining and minerals sector?

In the past years, organisations in the public and private sectors have attempted to embraced women in mining and minerals sector leadership positions. Outstanding examples include the outgoing Chamber of MINES Zimbabwe First female president - Ms Elizabeth Nerwande, Zimplats Chief Finance Officer - Patricia Zvandasara, Zimplats Head Corporate Affairs Mrs B Chindowe and Small scale artisanal Miners Federation Apolonia Munzverengi. In addition, for women to confront inherent mining-related barriers, they are encouraged to forming their own Women's Associations that tackle issues inhibiting them from having smooth flow operations in their mining and minerals sector operations.

The mining and minerals sector value chain depends on other value chain players, mainly in the services and related supplies. Role models in the mining industry support services include Finance and banking professionals - Patricia Zvandasara (Zimplats), Pindi Nyandoro (Standard Bank), Sibongile Moyo (Nedbank), Corporate affairs gurus in Matilda Nyathi (CBZ Holdings), Busi Chindove (Zimplats), and Lillian Hapanyengwi (Standard Chartered) among others.

Women role models have a significant in leading their mentees to Develop unique tailored made programs and training to attract other Indigenous women from communities close to mine sites. Whilst I am personally not a proponent of affirmative action policies, some argue that Government should consider introducing favourable affirmative action policies in the mining sector that promote gender equity and gender mainstreaming. Women entrepreneurs and women at the workplace, among other areas of life, need peace and tranquillity, and this would be achieved if Government Affirms and enforces zero-tolerance for gender-based violence

Further, government policy should Examine, adopt, and improve the national legal and regulatory framework to guarantee that women from mining communities have access to land and capital to promote their agency ultimately. Consistent and Deliberate research is necessary, including an Annual Women in Mining Surveys to understand the current experiences, developing trends, identify best practices, and expose tangible actions to drive women participation across all technical and professional roles.

\section{CONClusion}

Women remain underrepresented in Zimbabwe core mining operations despite the legislative efforts initiated by the Government towards their inclusion. For Zimbabwe to turn a corner, the country must embrace D\&I not as a 'women empowerment nice to do' but a competitive economic requirement because:

- Women leadership possess what Zimbabwe requires for the future

- Women leadership is the custodian of transformational thinking relevant ahead.

- Women leaders are better communicators and team players
- They bring versatility, bridge the gender gap, be accountable, and better manage processes and systems.

Zimbabwe Gender Commission to spearhead gender mainstreaming in all sectors, particularly the mining and minerals sector. Morally persued the players in the mining and minerals sector to embrace Reporting on diversity and inclusion in line with GRI standards. Government policy may consider a carrot and stick approach on companies that acknowledge and institute a balance in dealing with such key indicators as demographics, ethnicity, and the integrity of policies on $\mathrm{nD \& I}$ at the workplace.

\section{REFERENCES}

[1] Badenhorst, C.J. 2012. Women in Mining. 30th International Conference on Occupational Health, Cancun, Mexico

[2] Benya, A.P. 2009. Women in Mining: A challenge to occupational culture in mines. M.A. dissertation, University of the Witwatersrand, Johannesburg.

[3] Hinton, J., Hinton, B., \& Veiga, M. (2006). Women in artisanal and small scale mining in Africa. In K. Lahiri-Dutt, \& M. Macintyre, Women Miners in Developing Countries: Pit Women and Others

[4] Zungu, L. 2011. Women in the South African mining industry: an occupational health and safety perspective. Inaugural lecture

[5] Maame, E. and Eshun (2016) 'Women, Artisanal Mining and Peacebuilding in Africa: A Call to Action

[6] Khan, T. (2013). Mongolia: Raising Female Participation in the Large Scale Mining Sector

[7] Moyo, T. (2011). Extractive industries and women in southern Africa. BUWA! A Journal of African Women's Experiences (pp. 61-69). Open Society Initiative of Southern Africa

[8] Naidoo, B. (2015). Women in mining move to explosive levels.

[9] Scheepers, A. (2013). Women in Mining: Overcoming the challenge of occupational culture at the mines [Master's dissertation]. Stellenbosch University.

[10] Cohen, R. (2014). Extractive Desires: The Moral Control of Female Sexuality at Colombia's Gold Mining Frontier. The Journal of Latin American and Caribbean Anthropology

[11] Botha, D., \& Cronjé, F. (2014). Workplace opportunities for women employed in core mining activities. Mediterranean Journal of Social Sciences

[12] IWiM - International Women in Mining. (2016). Gender Pay Gap in Mining Sector

[13] Jenkins, K. (2014). Women, Mining and development: An emerging research agenda. The Extractive Industries and Society.

[14] Jenkins, K. (2017). Women anti-mining activists' narratives of everyday resistance in the Andes: staying put and carrying on in Peru and Ecuador. Gender, Place \& Culture.

[15] Abrahamsson, L., Segerstedt, E., Nygren, M., Johansson, J., Johansson, B. Edman, I., \& Åkerlund, A. (2014). Mining and Sustainable Development: Gender, Diversity and Work Conditions in Mining. Retrieved from Luleå tekniska universitet website: http://urn.kb.se/resolve?urn=urn:nbn:se:ltu:diva-22248

[16] Bird, F. (2016). The Practice of Mining and Inclusive Wealth Development in Developing Countries. Journal of Business Ethics, 135(4), 631-643. Retrieved August 27, 2021, from http://www.jstor.org/stable/24736095

[17] Hamann, R., Kapelus, P., Sonnenberg, D., Mackenzie, A., \& Hollesen, P. (2005). Local Governance as a Complex System: Lessons from Mining in South Africa, Mali and Zambia. The Journal of Corporate Citizenship, (18), 61-73. Retrieved August 27, 2021, from http://www.jstor.org/stable/jcorpciti.18.61

\section{AUTHORS}

First Author - Oswell Binha, PhD Candidate, Africa University, College of Business Peace Leadership and Governance 
International Journal of Scientific and Research Publications, Volume 11, Issue 9, September 2021

This publication is licensed under Creative Commons Attribution CC BY. 